\title{
Evaluation of the Clinical Pharmacist Role in a Health Care Team; a Comparative Approach
}

\author{
Mallesh M${ }^{1}$, Purushothama Reddy K², P. Vijaya Narasimha Reddy ${ }^{3}$ \\ ${ }^{1}$ Department of Pharmacy Practice, Sree Vidyanikethan College of Pharmacy, Tirupati, A.P - 516003, INDIA. \\ ${ }^{2}$ Department of Pharmacy Practice, Narayana Pharmacy College, Nellore, A.P - 516003, INDIA. \\ ${ }^{3}$ Department of General Medicine, Rajiv Gandhi Institute of Medical Sciences, Kadapa, A.P - 516003, INDIA.
}

\begin{abstract}
Background: Clinical pharmacy services were started in 1997 in India, in contrast to developed countries where the services were started in early 1960s. However 15 years have been passed out after the introduction of clinical pharmacy in India, but still the involvement of clinical pharmacist in the health care team is negligible. Objective: To elevate the clinical pharmacist role in the health care team, to justify the liaison between health care professionals and to promote better quality of life in chronic disease patients a prospective observational and interventional study was carried out. Setting: Rajiv Gandhi Institute of Medical Sciences, an 800 bedded tertiary care teaching hospital, Kadapa, India. Main Outcome: Progression of Quality of Life in chronic disease patients. Results: 200 patients were recruited belonging to age $\geq 40$ years; they were divided in to Observational Group (100) and Interventional Group (100). Each group consist of 25 patients for Hypertension (25), Stoke (25), Diabetes Mellitus (25) and Asthma (25). Major risk factors identified as age, obesity, cigarette smoking, hypercholesterolemia, alcohol, diet, hereditary, allergens, seasons. Laboratory levels were compared between groups with $p=0.0049$ (Observational Group), $p=0.0081$ (Interventional Group). Significant results obtained for medication adherence in Interventional Group $(p=0.0003)$, Knowledge, Aptitude and Practice assessment between groups yielded significant results in Interventional Group as follows in Hypertension $(p=<0.0001)$, Diabetes Mellitus $(p=<0.0001)$, Stroke $(p=<0.0001)$ and Asthma $(p=<0.0001)$. significant results were observed for Quality of Life in Interventional Group as follows Hypertension (Physical Components- $p=0.0036$; Mental Components - $p=<0.0001$ ), Diabetes Mellitus (Physical Components- $p=0.0221$; Mental Components $\mathrm{p}=0.0014$ ), Stroke (Physical Components- $\mathrm{p}=0.0015$; Mental Components- $\mathrm{p}=0.0038$ ) and Asthma (Physical Components- $p=0.0117$; Mental Components- $p=0.0043$ ). Conclusion: Clinical pharmacist role will be elevated in health care team by promoting intrinsic services to doctors, by maintaining the diplomatic liaison between health care professionals and a decent patient-pharmacist relation improves the patient's knowledge on disease and which makes their better Quality of Life.
\end{abstract}

Key Words: Pharm. D, Clinical Pharmacist, Quality of Life, Chronic Diseases, Health Care Team, KAP.

\section{INTRODUCTION}

"Clinical pharmacy is defined as that area of pharmacy concerned with the science and practice of rational medication use". ${ }^{1}$ Clinical pharmacy should be considered as an integral element of a health care system. Physicians can get assistance in optimizing patients' pharmacotherapy with the presence of clinical pharmacists in medical rounds. Furthermore, clinical pharmacists could condense medication errors and adverse effects insofar as they contribute meaningfully in the detection than management of drug related problems. ${ }^{2}$ The practice of clinical pharmacy embraces the

DOI: 10.5530/ijopp.9.4.5

concepts of both pharmaceutical care and management of medicines. ${ }^{3}$ It has beenmore than 75 years since the establishment of India's first degree in pharmacy. ${ }^{4}$ Clinical pharmacy services were started in 1997 in India, ${ }^{5}$ in contrast to United States where the services were started in early 1960s. However 15 years have been passed out after the introduction of clinical pharmacy in India, but still the involvement of clinical pharmacist in the health care team is negligible compared to the developed countries like United States, Australia etc. where the role of clinical pharmacist is being actively performed
Address for correspondence:

Dr. Mallesh. M (Pharm.D) Assistant Professor, Department of Pharmacy Practice, Sree Vidyanikethan College of Pharmacy,

Tirupati, AP. INDIA. Phone no: 9490570075 E-mail: malleshmandha2015@ gmail.com

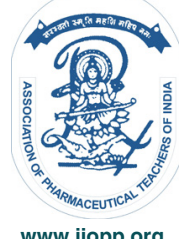

www.ijopp.org 
and accepted by all the health care professionals. Clinical pharmacy practice in the hospital settings, as seen in other countries, can improve the drug use process by promoting the quality and safe use of medicines thereby improving overall health care of the patients in India. Involvement of clinical pharmacists in patient care in the inpatient hospital settings results in safer and more effective medication use. ${ }^{4}$ As the chronic disease makes the patient to prone for more morbid and sometimes mortal conditions, the patients should be always empowered with the updated knowledge of his/her disease condition, medication and the proper life style modifications required to optimize their diseased condition and thereby improve their Quality of life, here comes the role of clinical pharmacist after the physician to educate the patients regarding their disease, medication and lifestyle modifications as a part of patient counseling. Hence there is a need to evaluate and elevate the role of clinical pharmacist services in the health care team. In the present study we are dealing with the provision of knowledge and improvement of quality of life of patients suffering with Hypertension, Stroke, Diabetes Mellitus (type II) and Asthma/COPD with the following objectives (1) to elevate the clinical pharmacist role in the health care team (2) to minimize Drug related problems (3) to justify the liaison between health care professionals(4) to provide the better knowledge to the chronic disease patients regarding their disease and medication (5) to promote better quality of life in chronic disease patients.

\section{AIM of the Study}

To Evaluate the Clinical Pharmacist Role in a Health Care Team by providing precise services to physicians, patients, nurses and other health care professionals in a tertiary care teaching hospital.

\section{Ethical Approval}

The study was approved by the Human Research Ethical committee,RIMS, Kadapa with approval number Rc. No. 3349/Acad./ 2013-14.

\section{METHOD}

Study design: Prospective Observational and Interventional Study

Study period: December 2013 to June 2014 (6 months)

Study population: 200 Patients belonging to HTN, DM, Stroke \& Asthma/COPD.
Study place: RIMS, an 800 bedded tertiary care teaching hospital, Kadapa.

Department: Department of General Medicine, male and female units (Inpatient)

Study Materials: Specially designed Patient data collection proforma (Apex-1), Clinical Pharmacist intervention forms, Patient information leaflets, KAP questionnaire (Apex-2, 3, 4, 5), SF-36 QOL questionnaire (Apex-6).

Inclusioncriteria:PatientssufferingfromHTN,DM, Stroke \& Asthma/COPD without any comorbid conditions/diseases with past history of 1 year belonging to age $\geq 40$ years.

Exclusion criteria: Acute diseased patients, immunosuppressive patients, chronickidney diseases, other cardiovascular diseases, pediatrics, pregnancy.

\section{Method of study}

Selection of patients based on the inclusion criteria followed by thecollection of all the baselineparameters of the patients'. Then patients were divided into two groups' namely observational and Interventional. Patients of intervention group received the clinical pharmacist's services along with the physician advices tothepatients, whereasthepatientsintheobservational group did not get intervened by the clinical pharmacist. The patientsincluded in theinterventional group were reviewed for every 3 months i.e. at $3^{\text {rd }}$ month and $6^{\text {th }}$ month during the study period, so that twice they can be counselled and educated. In contrast to this, patients in the observational group were asked to come at the $6^{\text {th }}$ month of study period after taking all the baseline parameters in the first month. Finally all the patients from both the groups were assessed for their quality of life and compared the same between the groups.

\section{RESULTS}

A total of 200 subjects were recruited in to the study based on the inclusion criteria, they were divided in to two groups namely observational group and interventional group. Out of 100 subjects, each disease (i.e. HTN, Stroke, DM II and Asthma/COPD) consists of 50 subjects of which 25 belong to observational and 25 to interventional groups. (Table 1 )

Table 2 furnishes the details of subjects' distribution based on the gender. More number of male patients were observed in the HTN (60\%) whereas female patients were seen more in the Asthma/COPD (56\%). 
Table 3 furnishes the details of subjects' distribution based on the age group. In HTN patients' highest number $(28 \%)$ was seen in the 51-60 years of age group. In Stroke patients' highest number $(30 \%)$ was seen in the 61-70 years of age group. In DM patients' highest number $(30 \%)$ was seen in the 61-70 years of age group. In Asthma/COPD patients' least number (16\%) was seen in the 71-80 years of age group and all other age groups consists of equal population (28\%).

Table 4 furnishes the details of subjects' distribution based on the duration of disease. In HTN patients' highest number (48\%) was seen in the 2-3 years of duration. In Stroke patients' highest number (40\%) was seen in the 2-3 years of duration. In DM patients' highest number $(40 \%)$ was seen in the $2-3$ years of duration. In Asthma/COPD patients' highest number (44\%) was seen in the 1-2 years of duration.

Table 5 describes the details of the risk factors contributing to the respective diseases. Age, hypercholesterolemia, obesity were recorded as the major risk factors for HTN. Age, hypercholesterolemia, obesity, alcohol were recorded as the major risk factors for Stroke. Age, hypercholesterolemia, obesity, diet, lifestyle were recorded as the major risk factors for DM, cigarette smoking, occupation, allergens, season were recorded as the major risk factors for Asthma/COPD.

Table 6 describes the details of effect of clinical pharmacist interventions, all the parameters mentioned in the table were affected by the clinical pharmacist counselling to the respective patients, general increase in HDL, FVC, FEV1 levels and decrease in all other parameters in the interventional group was observed. Contrasting results were seen in the observational group. All the results shown in the table are the standard deviation values of the laboratory parameters belonging to the respective patients. Significant result $\left(\mathrm{P}=0.0081^{* *}\right)$ was obtained for the interventional group.

Table 7 describes the details of subjects' distribution based on the adherence towards the medication. The values in the table represent the number of patients adhered towards medication in both the observational and interventional groups. Significance $(\mathrm{p})$ values were calculated for the yes answers that were adhered to medication. Significant result $(\mathrm{P}=0.0003)$ was obtained for the interventional group.

\section{Assessment of KAP for HTN, STROKE, DM II \& ASTHMA/COPD Patients}

KAP questionnaire scores for the HTN, DM II, STROKE \& ASTHMA/COPD patients were taken as yes $(\mathrm{Y})$ and no $(\mathrm{N})$ answers for the questions mentioned in the respective questionnaire. Significance $(\mathrm{p})$ value was calculated for the yes answers.
Table 1: Distribution of subjects into observational and interventional groups

\begin{tabular}{cccc} 
Disease & $\begin{array}{c}\text { Observation } \\
\text { Group }(\mathbf{n}- \\
\text { 100) }\end{array}$ & $\begin{array}{c}\text { Intervention } \\
\text { Group }(\mathbf{n}- \\
\mathbf{1 0 0})\end{array}$ & $\begin{array}{c}\text { Total } \\
\mathbf{N}=\mathbf{2 0 0}\end{array}$ \\
\hline HTN & 25 & 25 & 50 \\
STROKE & 25 & 25 & 50 \\
DM (II) & 25 & 25 & 50 \\
ASTHMA/ & 25 & 25 & 50 \\
COPD & 25 & & \\
\hline
\end{tabular}

Table 2: Distribution of subjects based on the gender

\begin{tabular}{|c|c|c|c|c|c|}
\hline \multirow[t]{2}{*}{ Disease } & \multirow[t]{2}{*}{ Gender } & \multirow{2}{*}{$\begin{array}{c}\text { Observation } \\
\text { Group }\end{array}$} & \multirow{2}{*}{$\begin{array}{l}\text { Intervention } \\
\text { Group }\end{array}$} & \multicolumn{2}{|c|}{$\begin{array}{l}\text { Weighted } \\
\text { Total (50) }\end{array}$} \\
\hline & & & & (n) & $\{\%\}$ \\
\hline \multirow{2}{*}{ HTN } & Male & 15 & 15 & 30 & 60 \\
\hline & Female & 10 & 10 & 20 & 40 \\
\hline \multirow{2}{*}{ STROKE } & Male & 17 & 10 & 27 & 54 \\
\hline & Female & 8 & 15 & 23 & 46 \\
\hline \multirow{2}{*}{ DM (II) } & Male & 11 & 12 & 23 & 46 \\
\hline & Female & 14 & 13 & 27 & 54 \\
\hline \multirow{2}{*}{$\begin{array}{l}\text { ASTHMA/ } \\
\text { COPD }\end{array}$} & Male & 12 & 10 & 22 & 44 \\
\hline & Female & 13 & 15 & 28 & 56 \\
\hline
\end{tabular}

Note: KAP questionnaire and patient's answers are given in the Appendix 1

\section{Assessment of KAP for HTN Patients}

KAP questionnaire scores for the HTN patients in the observational group which were taken as yes $(\mathrm{Y})$ and no (N) answers for 26 questions mentioned in the questionnaire.

\section{Assessment of KAP for Stroke Patients}

KAP questionnaire scores for the Stroke patients in the observational group which were taken as yes $(\mathrm{Y})$ and no $(\mathrm{N})$ answers for 23 questions mentioned in the questionnaire.

\section{Assessment of KAP for DM Patients}

KAP questionnaire scores for the DM patients in the observational group which were taken as yes $(\mathrm{Y})$ and no $(\mathrm{N})$ answers for 24 questions mentioned in the questionnaire.

\section{Assessment of KAP for Asthma/COPD Patients}

KAP questionnaire scores for the Asthma/COPD patients in the observational group which were taken as yes $(\mathrm{Y})$ and no $(\mathrm{N})$ answers for 21 questions mentioned in the questionnaire.

Assessment of QOL for HTN, Stroke, DM and Asthma/COPD Patients

Indian Journal of Pharmacy Practice, Vol 9, Issue 4, Oct-Dec, 2016 
Table 3: Distribution of subjects based on the Age Group

\begin{tabular}{|c|c|c|c|c|c|c|}
\hline \multirow{2}{*}{ Disease } & \multirow{2}{*}{ Age Group (Years) } & \multirow{2}{*}{$\begin{array}{c}\text { Observation Group } \\
\mathrm{M} / \mathrm{F}\end{array}$} & \multirow{2}{*}{$\begin{array}{c}\text { Intervention Group } \\
\mathrm{M} / \mathrm{F}\end{array}$} & \multicolumn{3}{|c|}{ Weighted Total (50) } \\
\hline & & & & M/F & (n) & $\{\%\}$ \\
\hline \multirow{4}{*}{ HTN } & $40-50$ & $3 / 3$ & $3 / 4$ & $6 / 7$ & 13 & 26 \\
\hline & $51-60$ & $3 / 3$ & $4 / 4$ & $7 / 7$ & 14 & 28 \\
\hline & $61-70$ & $3 / 3$ & $3 / 4$ & $6 / 7$ & 13 & 26 \\
\hline & $71-80$ & $2 / 3$ & $2 / 3$ & $4 / 5$ & 10 & 20 \\
\hline \multirow{4}{*}{ STROKE } & $40-50$ & $3 / 4$ & $3 / 3$ & $6 / 7$ & 13 & 26 \\
\hline & $51-60$ & $3 / 3$ & $3 / 4$ & $6 / 7$ & 13 & 26 \\
\hline & $61-70$ & $6 / 2$ & $5 / 2$ & $11 / 4$ & 15 & 30 \\
\hline & $71-80$ & $3 / 2$ & $2 / 2$ & $5 / 4$ & 9 & 18 \\
\hline \multirow{4}{*}{ DM (II) } & $40-50$ & $3 / 2$ & $3 / 3$ & $6 / 5$ & 11 & 22 \\
\hline & $51-60$ & $3 / 3$ & $4 / 3$ & $7 / 6$ & 13 & 26 \\
\hline & $61-70$ & $5 / 2$ & $5 / 3$ & $10 / 5$ & 15 & 30 \\
\hline & $71-80$ & $3 / 2$ & $3 / 3$ & $6 / 5$ & 11 & 22 \\
\hline \multirow{4}{*}{$\begin{array}{l}\text { ASTHMA/ } \\
\text { COPD }\end{array}$} & $40-50$ & $3 / 3$ & $4 / 4$ & $7 / 7$ & 14 & 28 \\
\hline & $51-60$ & $3 / 3$ & $4 / 4$ & $7 / 7$ & 14 & 28 \\
\hline & $61-70$ & $3 / 3$ & $4 / 4$ & $7 / 7$ & 14 & 28 \\
\hline & $71-80$ & $2 / 2$ & $2 / 2$ & $4 / 4$ & 8 & 16 \\
\hline
\end{tabular}

Table 4: Distribution of subjects based on the Duration of Disease

\begin{tabular}{|c|c|c|c|c|c|}
\hline \multirow{2}{*}{ Disease } & \multirow{2}{*}{ Duration (Years) } & \multirow{2}{*}{$\begin{array}{c}\text { Observation Group } \\
n\end{array}$} & \multirow{2}{*}{$\begin{array}{c}\text { Intervention } \\
\text { Group } \\
\mathbf{n}\end{array}$} & \multicolumn{2}{|c|}{ Weighted Total (50) } \\
\hline & & & & $\mathbf{n}$ & $\{\%\}$ \\
\hline \multirow{3}{*}{ HTN } & $1-2$ & 6 & 6 & 12 & 24 \\
\hline & $2-3$ & 12 & 12 & 24 & 48 \\
\hline & $\square 3$ & 7 & 7 & 14 & 28 \\
\hline \multirow{3}{*}{ STROKE } & $1-2$ & 9 & 9 & 18 & 36 \\
\hline & $2-3$ & 10 & 10 & 20 & 40 \\
\hline & $\square 3$ & 6 & 6 & 12 & 24 \\
\hline \multirow{3}{*}{ DM (II) } & $1-2$ & 9 & 7 & 17 & 34 \\
\hline & $2-3$ & 10 & 10 & 20 & 40 \\
\hline & $\square 3$ & 7 & 6 & 13 & 26 \\
\hline \multirow{3}{*}{ ASTHMA/COPD } & $1-2$ & 11 & 11 & 22 & 44 \\
\hline & $2-3$ & 8 & 8 & 16 & 32 \\
\hline & 3 & 6 & 6 & 12 & 24 \\
\hline
\end{tabular}

\begin{tabular}{|c|c|c|c|c|}
\hline Disease & HTN & Stroke & DM (II) & $\begin{array}{l}\text { Asthma/ } \\
\text { COPD }\end{array}$ \\
\hline Risk Factors & $\begin{array}{c}\text { Age } \\
\text { Obesity } \\
\text { Cigarette smoking } \\
\text { Hypercholesterolemia } \\
\text { Alcohol } \\
\text { Diet } \\
\text { Hereditary } \\
\text { Life style }\end{array}$ & $\begin{array}{c}\text { Age } \geq 60 \\
\text { Obesity } \\
\text { Cigarette smoking } \\
\text { Hypercholesterolemia } \\
\text { Alcohol } \\
\text { Diet } \\
\text { Uncontrolled HTN } \\
\text { Trauma } \\
\text { Life style }\end{array}$ & $\begin{array}{c}\text { Age } \\
\text { Obesity } \\
\text { Hypercholesterolemia } \\
\text { Hereditary } \\
\text { Diet } \\
\text { Life style }\end{array}$ & $\begin{array}{c}\text { Age } \\
\text { Smoke/fog } \\
\text { Cigarette smoking } \\
\text { Occupation } \\
\text { Diet } \\
\text { Hereditary } \\
\text { Allergens } \\
\text { Seasons } \\
\text { Viral }\end{array}$ \\
\hline
\end{tabular}


Table 6: Effect of Clinical Pharmacist Intervention

\begin{tabular}{|c|c|c|c|c|c|c|c|c|}
\hline \multirow{2}{*}{ Disease } & \multirow{2}{*}{ Parameter } & \multicolumn{3}{|c|}{ Observational } & \multicolumn{4}{|c|}{ Interventional } \\
\hline & & Base-line & End & $p$ & Base-line & $3 \mathrm{M}$ & $6 \mathrm{M}$ & p \\
\hline HTN & $\mathrm{BP}(\mathrm{mmHg})$ & $160 \pm 9$ & $162 \pm 11$ & & $168 \pm 7$ & $160 \pm 4$ & $158 \pm 3$ & \\
\hline \multirow{4}{*}{ STROKE } & $\mathrm{BP}(\mathrm{mmHg})$ & $170 \pm 7$ & $182 \pm 8$ & & $181 \pm 4$ & $174 \pm 5$ & $162 \pm 7$ & \\
\hline & $\mathrm{HDL}(\mathrm{mg} / \mathrm{dl})$ & $37 \pm 2$ & $36 \pm 2$ & & $35 \pm 2$ & $38 \pm 1$ & $39 \pm 3$ & \\
\hline & $\operatorname{LDL}(\mathrm{mg} / \mathrm{dl})$ & $95 \pm 5$ & $105 \pm 6$ & & $97 \pm 5$ & $82 \pm 3$ & $79 \pm 2$ & \\
\hline & $\mathrm{TC}(\mathrm{mg} / \mathrm{dl})$ & $145 \pm 7$ & $152 \pm 9$ & & $148 \pm 9$ & $140 \pm 5$ & $136 \pm 2$ & \\
\hline \multirow{5}{*}{ DM (II) } & RBS (mg/dl) & $224 \pm 8$ & $231 \pm 5$ & & $235 \pm 6$ & $198 \pm 8$ & $164 \pm 2$ & \\
\hline & $\mathrm{FBS}(\mathrm{mg} / \mathrm{dl})$ & $146 \pm 6$ & $151 \pm 4$ & & $153 \pm 4$ & $146 \pm 4$ & $140 \pm 2$ & \\
\hline & $\mathrm{HDL}(\mathrm{mg} / \mathrm{dl})$ & $35 \pm 2$ & $36 \pm 2$ & 0.0049 & $35 \pm 1$ & $38 \pm 3$ & $42 \pm 2$ & 0.0081 \\
\hline & LDL(mg/dl) & $105 \pm 4$ & $108 \pm 4$ & & $104 \pm 7$ & $98 \pm 5$ & $82 \pm 2$ & \\
\hline & $\mathrm{TC}(\mathrm{mg} / \mathrm{dl})$ & $135 \pm 7$ & $142 \pm 5$ & & $152 \pm 4$ & $144 \pm 2$ & $131 \pm 2$ & \\
\hline \multirow{5}{*}{$\begin{array}{l}\text { ASTHMA/ } \\
\text { COPD }\end{array}$} & $\mathrm{RR}(\mathrm{c} / \mathrm{m})$ & $24 \pm 2$ & $24 \pm 4$ & & $25 \pm 4$ & $22 \pm 2$ & $20 \pm 2$ & \\
\hline & FVC (L) & $2.6 \pm 1.2$ & $2.4 \pm 1.1$ & & $2.1 \pm 1.4$ & $2.9 \pm 1.0$ & $3.5 \pm 1.3$ & \\
\hline & FEV1 (L) & $2.2 \pm 0.3$ & $2 \pm 1.1$ & & $2 \pm 1.3$ & $2.6 \pm 2.1$ & $2.9 \pm 1.9$ & \\
\hline & TLC (L) & $6.9 \pm 1.7$ & $7.2 \pm 1.1$ & & $6.9 \pm 1.5$ & $6.9 \pm 0.4$ & $6.5 \pm 1.0$ & \\
\hline & VC (L) & $1.8 \pm 1.1$ & $2.1 \pm 1.4$ & & $1.9 \pm 1.2$ & $1.8 \pm 0.5$ & $1.7 \pm 0.6$ & \\
\hline
\end{tabular}

Observational Group Significance - Student paired t-test; $p=0.0049$ (s)

Interventional Group Significance - one way ANOVA; $p=0.0081 * *(s)$

\begin{tabular}{|c|c|c|c|c|c|c|c|c|c|c|c|c|}
\hline \multirow{3}{*}{ Disease } & \multicolumn{4}{|c|}{$\begin{array}{l}\text { Observational } \\
\text { Adherence }\end{array}$} & \multicolumn{7}{|c|}{$\begin{array}{c}\text { Interventional } \\
\text { Adherence }\end{array}$} & \multirow{3}{*}{ P-Value } \\
\hline & \multicolumn{2}{|c|}{ Baseline } & \multicolumn{2}{|c|}{ End } & \multirow[t]{2}{*}{ P-Value } & \multicolumn{2}{|c|}{ Baseline } & \multicolumn{2}{|c|}{$3 M$} & \multicolumn{2}{|c|}{$6 M$} & \\
\hline & Yes & No & Yes & No & & $\mathbf{Y}$ & $\mathbf{N}$ & $\mathbf{Y}$ & $\mathbf{N}$ & $\mathbf{Y}$ & $\mathbf{N}$ & \\
\hline HTN & 12 & 13 & 11 & 14 & & 12 & 13 & 14 & 11 & 19 & 6 & \\
\hline STROKE & 13 & 12 & 13 & 12 & & 11 & 14 & 11 & 14 & 15 & 10 & \\
\hline & & & & & 0.4444 & & & & & & & 0.0003 \\
\hline DM (II) & 14 & 11 & 11 & 14 & & 11 & 14 & 11 & 14 & 19 & 6 & \\
\hline ASTHMA/COPD & 13 & 12 & 14 & 11 & & 13 & 12 & 15 & 10 & 20 & 5 & \\
\hline
\end{tabular}

Observational Group Significance - Student paired t-test; $p=0.4444$ (ns) Interventional Group Significance - one way ANOVA; $p=0.0003^{* * *}(\mathrm{~s})$

QOL questionnaire (SF-36) consists of 35 questions for each disease divided in to physical and mental components. Each component is divided into different questions hence an average score was taken for all the patients and compared the same for significance.

\section{DISCUSSION}

A prior ethical clearance was obtained from Institutional Ethical Committee (IEC) of RIMS and with the permission of head of the Department of General Medicine, RIMS; the study was begun conferring to the methodology. All the statistical analysis were calculated by using the student paired t-Test and one way ANOVA with graph pad prism software taking $P=<0.05$ as significant value.

Highest number of male population was found in HTN which coincide with the results of Biradar S S. et al. ${ }^{6}$ In the interventional group in HTN patients, $\mathrm{BP}(\mathrm{mmHg})$ decreased from $168 \pm 7$ to $158 \pm 3$, in Stroke patients BP decreased from $181 \pm 4$ to $162 \pm 7$, in Stroke patients HDL $(\mathrm{mg} / \mathrm{dl})$ levels increased from $35 \pm 2$ to $39 \pm 3$, $\mathrm{LDL}(\mathrm{mg} / \mathrm{dl})$ levels decreased from $97 \pm 5$ to $79 \pm 2$, TC $(\mathrm{mg} / \mathrm{dl})$ levels decreased from $148 \pm 9$ to $136 \pm 2$. These results coincide with the results of Autumn Bagwell, 
Pharm D etal. ${ }^{7}$ n DM patients RBS levels decreased from $235 \pm 6$ to $164 \pm 2$, FBS levels decreased from 153 \pm 4 to $140 \pm 2$, HDL levels increased from $35 \pm 1$ to 38 \pm 3 , LDL levels decreased from $104 \pm 7$ to $82 \pm 2$, TC levels decreased from $152 \pm 4$ to $131 \pm 2$. These results coincide with the results of Taha O. Mahwiet al. ${ }^{8}$

Significant results were obtained in the medication adherence behaviour of the patients in the interventional group with significance value $p-0.0001^{* * *} \mathrm{com}-$ pared to the observational group $p-0.4444$.

KAP questionnaires were used to assess the patient's knowledge regarding their disease, medication and life style adaptations they have to follow to control their morbid conditions and to improve their QOL. Separate questionnaires were prepared for HTN, Stroke, DM and Asthma/COPD patients. Results were compared between the observational and interventional groups. Both groups were assessed separately taking scores at the baseline and at the end of the study and significance were calculated.

For HTN patients KAP questionnaire consists of 26 questions for these questions answers were taken from the patients and significance was calculated, scores as follows (Figure 1 and 2). In the observational group $p=0.0010^{* * *}(\mathrm{~s})$, in the interventional group $p=<0.0001^{* * *}(\mathrm{~s})$. These results coincide with the Line Aubert et al. ${ }^{9}$

For Stroke patients KAP questionnaire consists of 23 questions for these questions answers were taken from the patients and significance was calculated, scores as follows (Figure 3 and 4 ). In the observational group $p=0.0007^{* *}(\mathrm{~s})$. In the interventional group $p=<0.0001^{* * *}(\mathrm{~s})$, Greater significant difference was observed, results coincides with the Sujata Das et al. ${ }^{10}$

\section{KAP for HTN OBG}

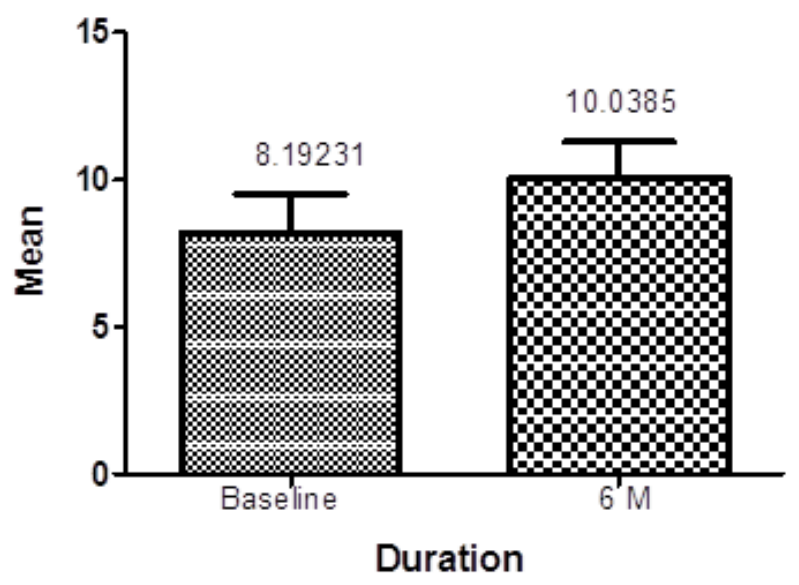

Figure 1: Assessment of KAP for HTN Patients (Observational group) Significance - Student paired t-test; $p=0.0024^{\star \star}(s)$.
For DM patients KAP questionnaire consists of 24 questions for these questions answers were taken from the patients and significance was calculated, scores as follows (Figure 5 and 6 ). In the observational group $p=0.0006^{* * *}$ $(\mathrm{s})$, in the interventional group $p=<0.0001^{* * *}(\mathrm{~s})$. These results coincide with the Al-Maskar et al. ${ }^{11}$

For Asthma/COPD patients KAP questionnaire consists of 21 questions for these questions answers were taken from the patients and significance was calculated, scores as follows (Figure 7 and 8 ). In the observational group $p=0.0126^{*}(\mathrm{~ns})$, in the interventional group $p=<0.0001^{* * *}(\mathrm{~s})$ and these results coincides with the Rathan Shyam M, Jyothi D. ${ }^{12}$

QOL questionnaires were used to assess the patient's quality of life before and after the interventions by the clinical pharmacist. Same questionnaire was used for HTN, Stroke, DM and Asthma/COPD patients which consists of 35 questions relating to the physical and mental health components. As the each question was related to all the diseased patients and the patients from each disease may or may not have the same answer for the same question and sometimes single question may get more yes answers from different patients, hence an average score was taken for the assessment of significance value. Results were compared between the observational and interventional groups.

For HTN patients QOL was assessed and the scores as follows (Figure 9-12). In the observational group for the Physical Components $p=0.1573$ (ns), for the Mental Components $p=0.0835$ (ns). In the interventional group for the Physical Components $p=0.0036^{* *}(s)$, for the Mental Components $p=<0.0001^{* * *}(\mathrm{~s})$. Greater significant difference was observed. These coincide with the Gusmao JL et al. ${ }^{13}$

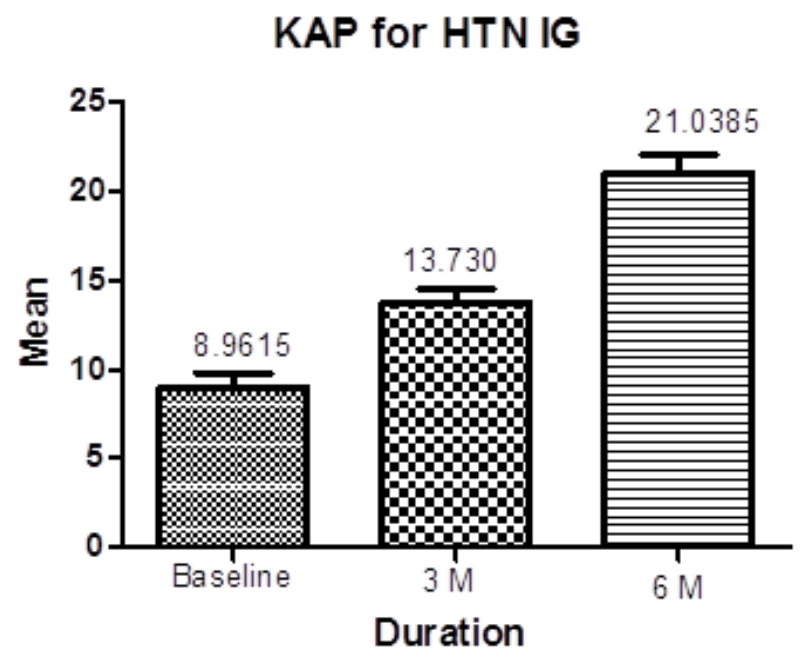

Figure 2: Assessment of KAP for HTN Patients (Interventional group) Significance - one way ANOVA; $p=<0.0001^{\star * *}(s)$. 


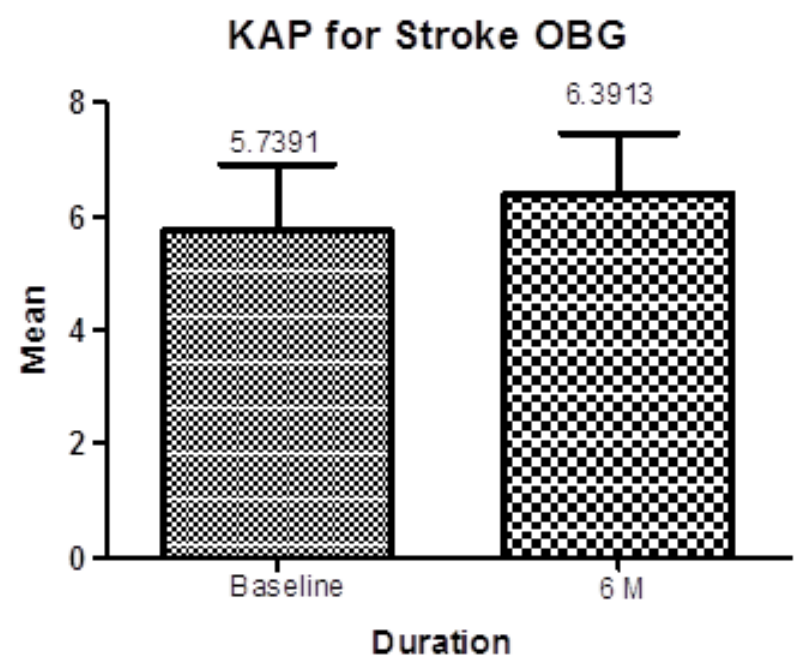

Figure 3: Assessment of KAP for Stroke Patients (Observational group) Significance - Student paired t-test; $p=0.0873$ (ns).

\section{KAP for Stroke IG}

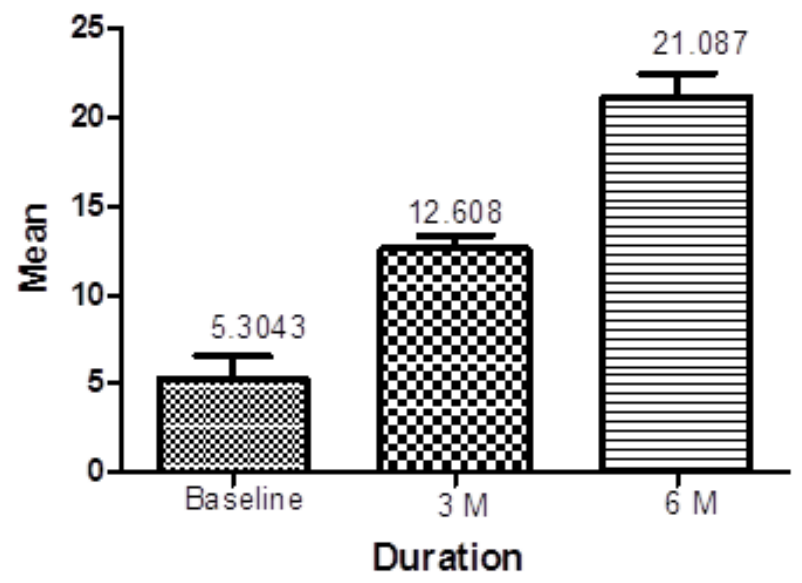

Figure 4: Assessment of KAP for Stroke Patients (Interventional group) Significance - one way ANOVA; $p=<0.0001^{\star * *}(s)$.

\section{KAP for DM OBG}

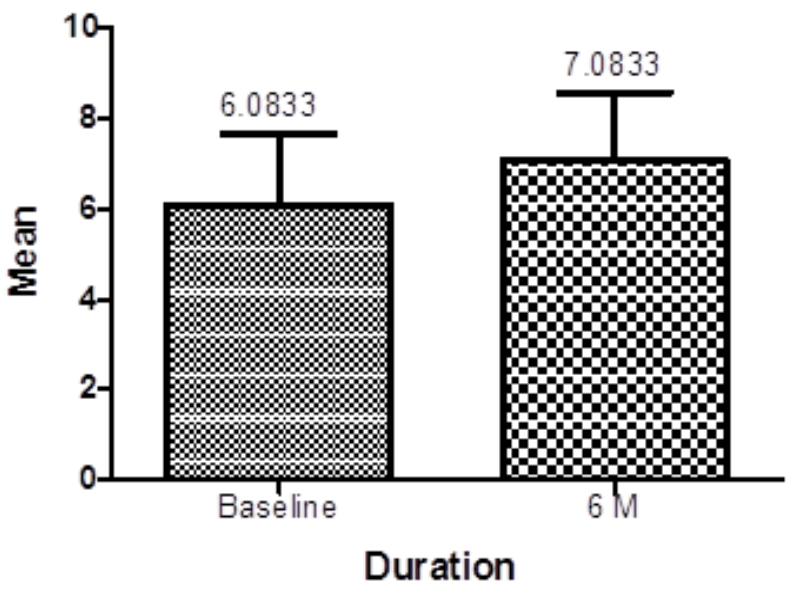

Figure 5: Assessment of KAP for DM Patients (Observational group) Significance - Student paired t-test; $p=0.0025^{\star \star}(s)$
KAP for DM IG

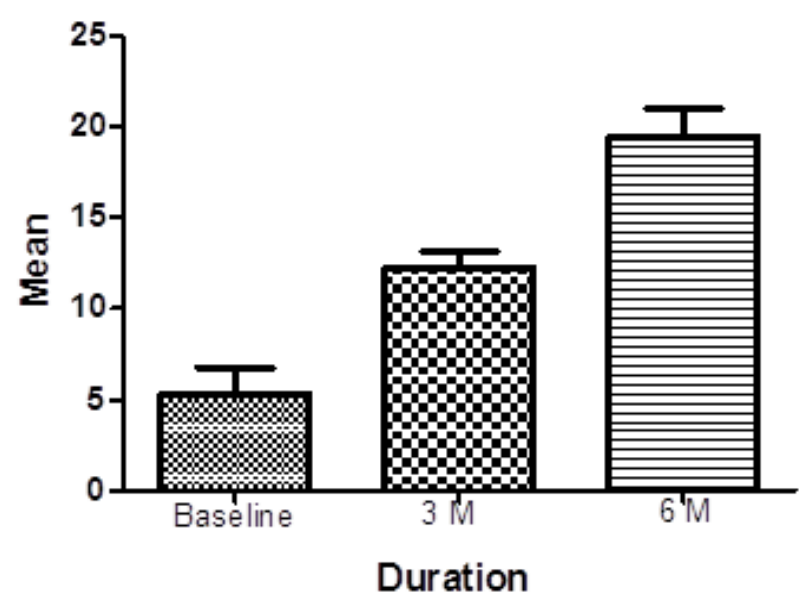

Figure 6: Assessment of KAP for DM Patients (Interventional group) Significance - one way ANOVA; $p=<0.0001^{* \star *}(s)$.

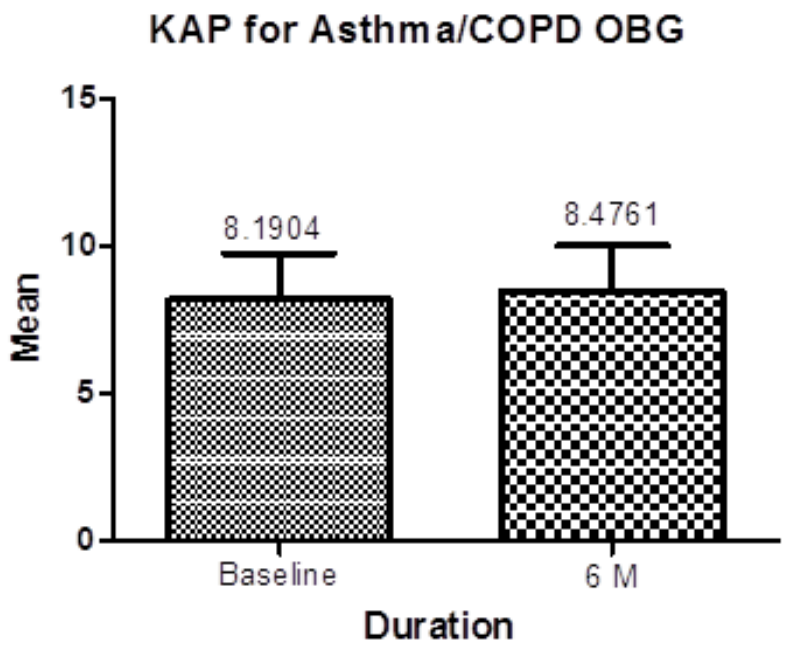

Figure 7: Assessment of KAP for COPD Patients (Observational group) Significance - Student paired t-test; $p=0.1623$ (ns)..

\section{KAP for Asthm a/COPD IG}

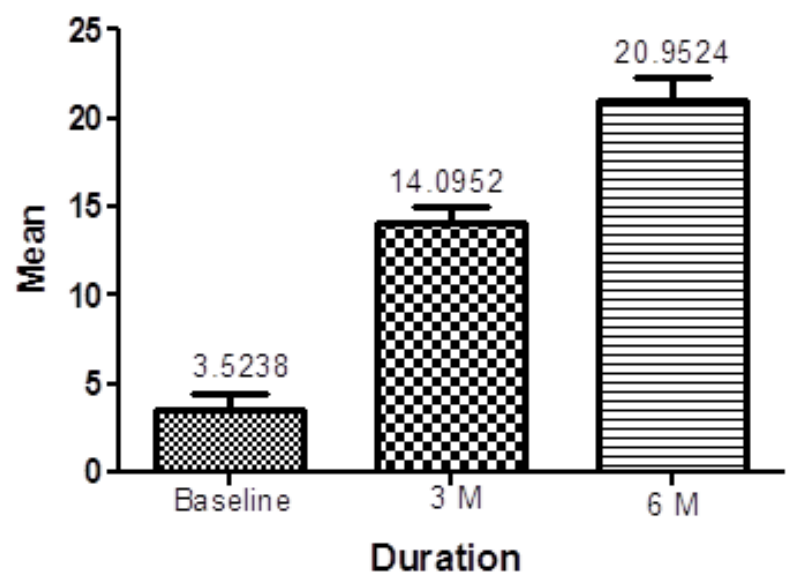

Figure 8: Assessment of KAP for COPD Patients (Interventional group) Significance - one way ANOVA; $p=<0.0001^{\star * *}$ (s).

Indian Journal of Pharmacy Practice, Vol 9, Issue 4, Oct-Dec, 2016 
For Stroke patients in the observational group, for the Physical Components $p=0.0798$ (ns), for the Mental Components $p=0.5017$ (ns). In the interventional group for the Physical Components $p=0.0015^{* *}(s)$, for the Mental Components $p=0.0038^{* *}(s)$ (Figure 13-16). These results coincide with the Kehchung Lin et al. ${ }^{14}$

For DM patients in the observational group for the Physical Components $p=0.1761$ (ns), for the Men- tal Components $p=0.1161$ (ns). In the interventional group for the Physical Components $p=0.0221^{*}(s)$, for the Mental Components $p=0.0014^{* *}(s)$ (Figure 17-20). These results coincide with the Harvey Thomson et al. ${ }^{15}$ For Asthma/COPD patients in the observational group for the Physical Components $p=0.0328^{*}(s)$, for the Mental Components Significance $p=0.1672$ (ns). In the interventional group for the Physical Components

\section{QOL for HTN OBG}

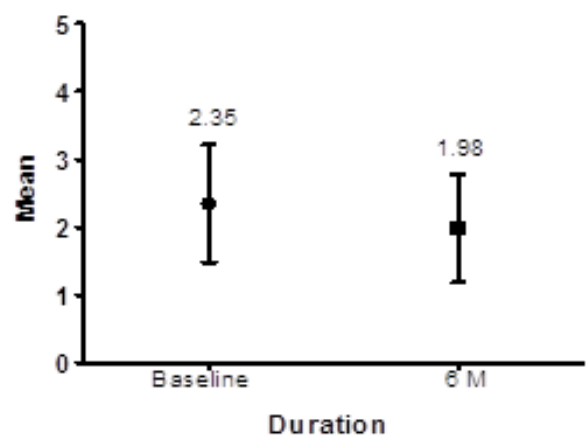

QOL for HTN OBG

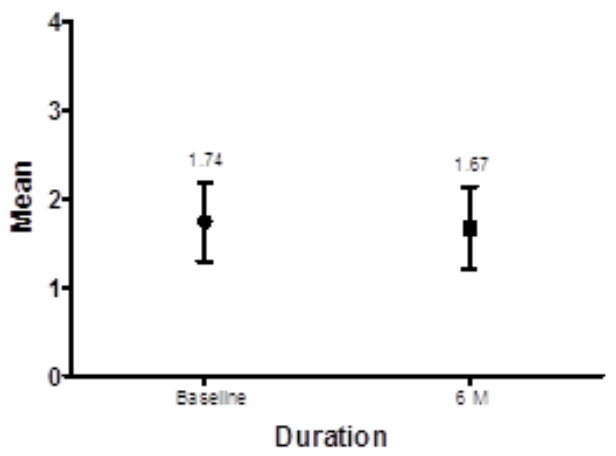

Figure 9,10: Assessment of QOL for HTN Patients (Observational group). (Figure 9) Physical Components Significance - Student paired t-test; $p=0.1573(n s)$. (Figure 10) Mental Components Significance - Student paired t-test; $p=0.0835$ (ns).

QOL for HTN IG

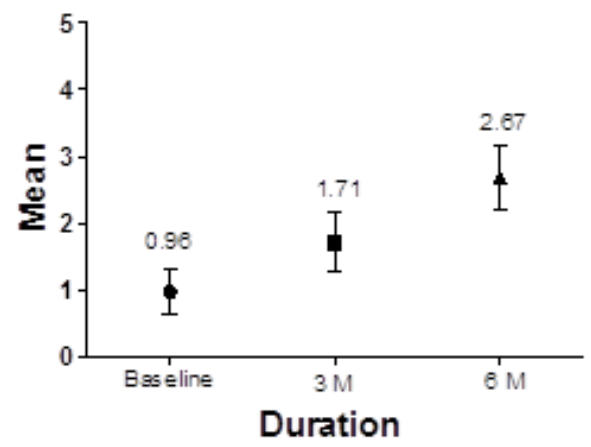

QOL for HTN IG

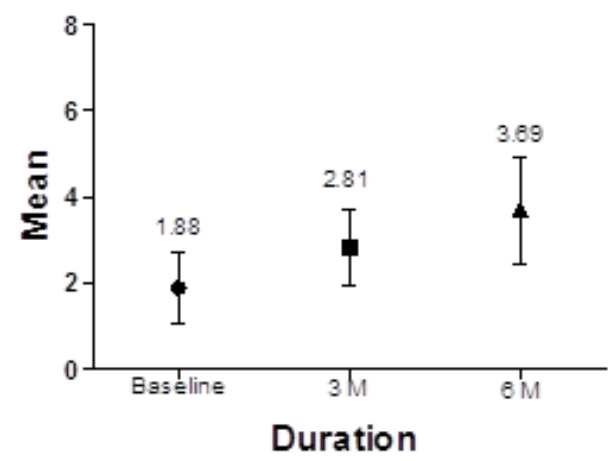

Figure 11,12: Assessment of QOL for HTN Patients (Interventional group). (Figure 11) Physical Components Significance-one way ANOVA; $p=0.0036^{* *}(s)$. (Figure 12) Mental Components Significance - one way ANOVA; $p=<0.0001^{\star * *}(s)$

QOL for Stroke OBG

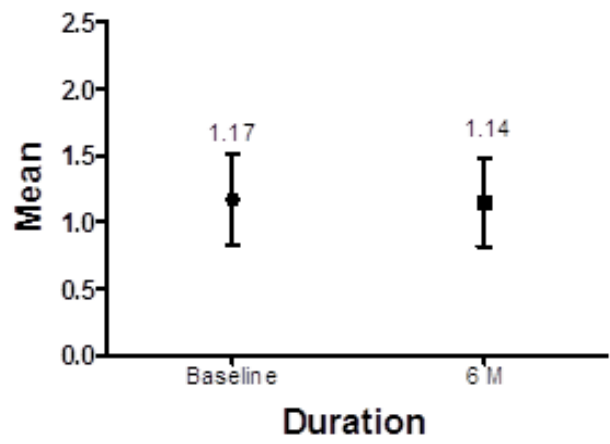

QOL for Stroke OBG

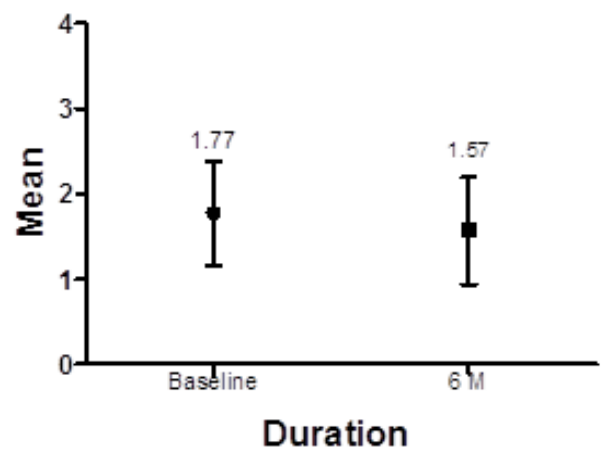

Figure 13,14: Assessment of QOL for HTN Patients (Observational group) . (Figure 13) Physical Components Significance-Student paired t-test; $p=0.0798(n s)$. (Figure 14) Mental Components Significance - Student paired t-test; $p=0.5017$ (ns). 
$p=0.0117^{*}(s)$, for the Mental Components $p=0.0043^{* *}$

(s) (Figure 21-24). These results coincide with the Eanes

Delgado Barros Pereiral et al. ${ }^{16}$

\section{CONCLUSION}

Our study revealed that the intrinsic services provided by the clinical pharmacist in the hospital settings are the mediums for a clinical pharmacist to take part in the health care team and it can be achieved with the diplomatic relation maintained with all the other health care professionals in fact sometimes clinical pharmacist may
QOL for Stroke IG

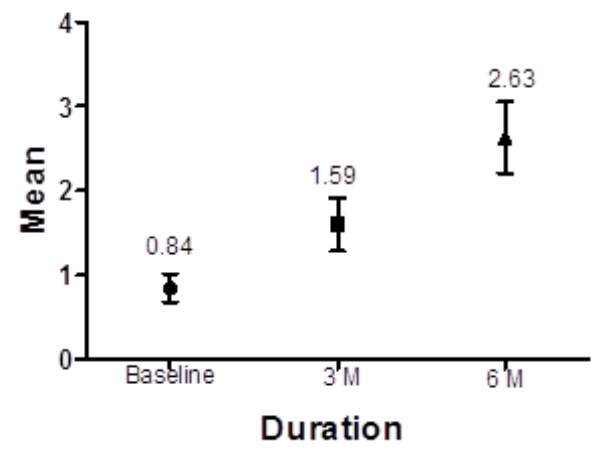

QOL for Stroke IG

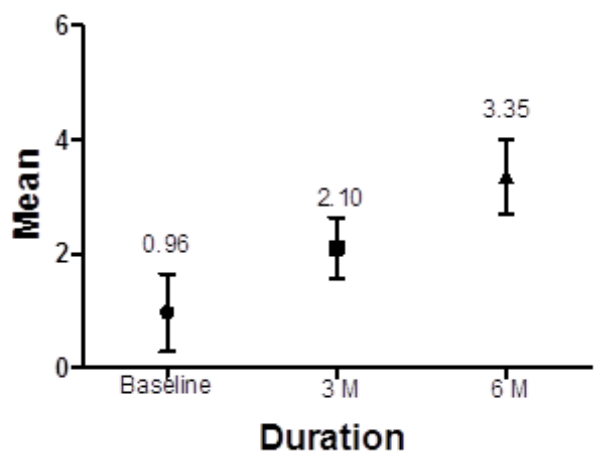

Figure 15,16: Assessment of QOL for Stroke Patients (Interventional group). (Figure 15) Physical Components Significance - one way ANOVA; $p=0.0015^{\star *}(s)$. (Figure 16) Mental Components Significance - one way ANOVA; $p=0.0038^{* *}(s)$.

QOL for DM OBG

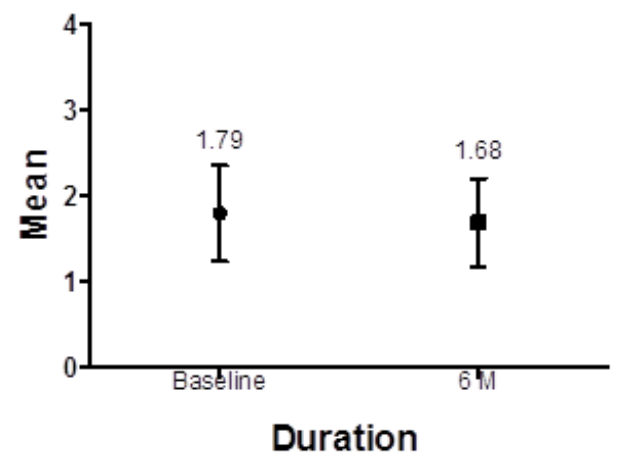

QOL for DM OBG

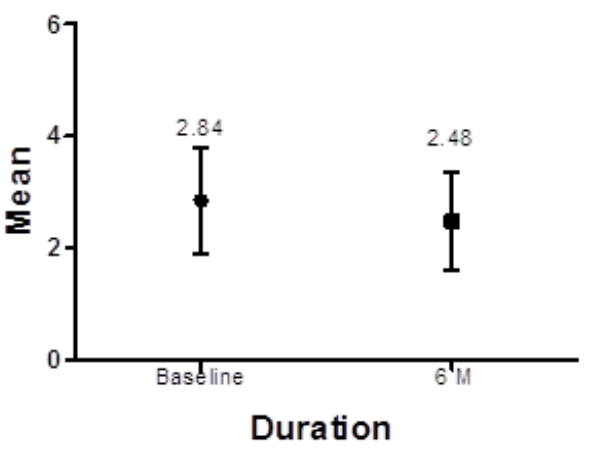

Figure 17,18: Assessment of QOL for DM Patients (Observational group) . (Figure 17) Physical Components Significance-Student paired t-test; $p=0.1761$ (ns). (Figure 18) Mental Components Significance - Student paired t-test; $p=0.1161$ (ns).

QOL for DM IG

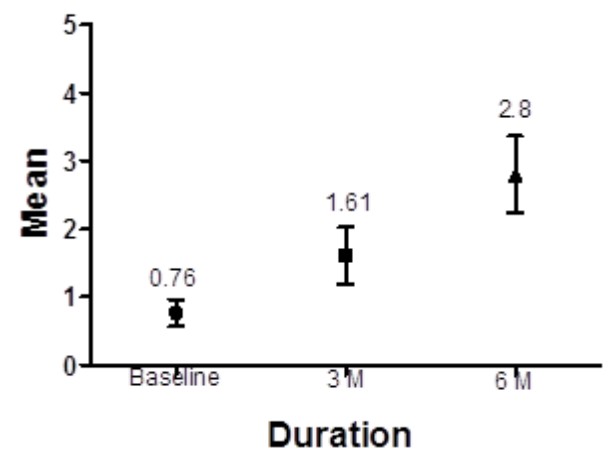

QOL for DM IG

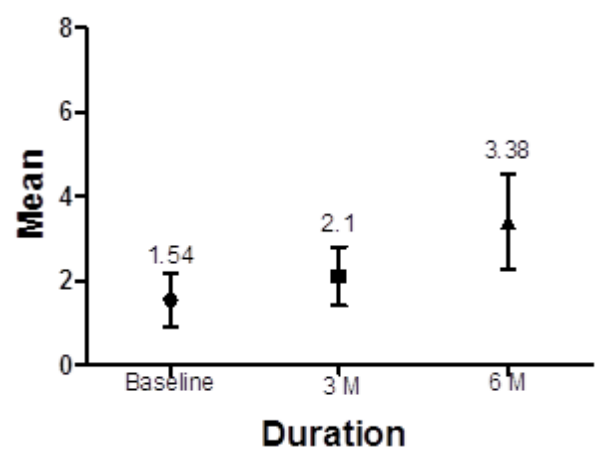

Figure 19, 20: Assessment of QOL for DM Patients (Interventional group). (Figure 19) Physical Components Significance - one way ANOVA; $p=0.0221^{\star}(\mathrm{s})$. (Figure 20) Mental Components Significance - one way ANOVA; $p=0.0014^{\star *}(\mathrm{~s})$. 
QOL for Asthma OBG

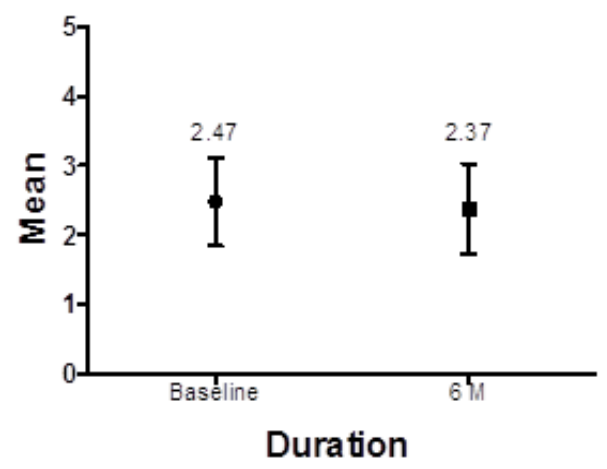

QOL for Asthma OBG

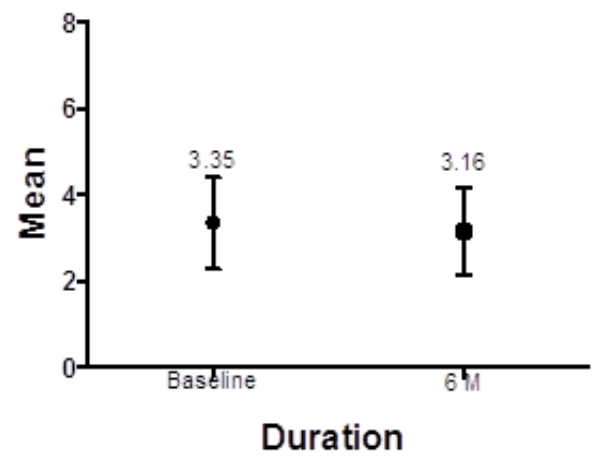

Figure 21, 22: Assessment of QOL for Asthma/COPD Patients (Observational group). (Figure 21) Physical Components Significance - Student paired t-test; $p=0.0328^{*}(\mathrm{~s})$. (Figure 22) Mental Components Significance - Student paired t-test; $p=0.1672$ (ns).

QOL for Asthma IG

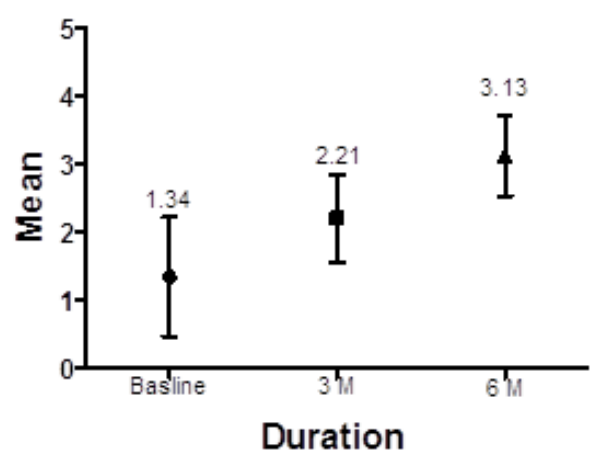

QOL for As thma IG

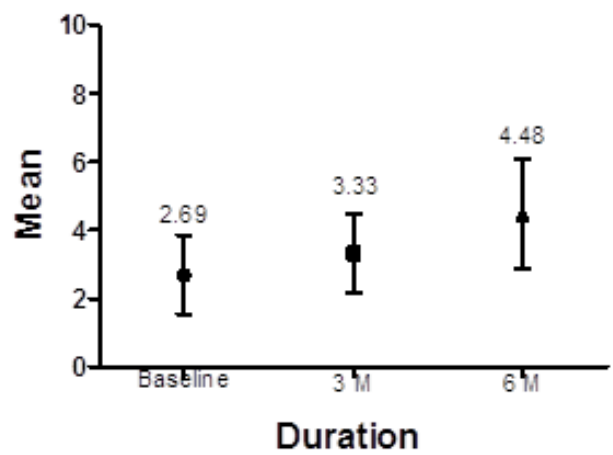

Figure 23, 24: Assessment of QOL for Asthma/COPD Patients (Interventional group). (Figure 23) Physical Components Significance - one way ANOVA; $p=0.0117^{\star}(\mathrm{s})$. (Figure 24) Mental Components Significance - one way ANOVA; $p=0.0043^{\star \star}(\mathrm{s})$.

go beyond it and can achieve decent outcomes thereby better liaison will be ascertained between the clinical pharmacist and all other health care professionals. Study mentions the importance of clinical pharmacists in improving the adherence to medication in the chronic disease patients thereby achieving the noble therapeutic levels of the medicines which lead to the well improvement of patient. Study also stresses the role of the clinical pharmacist in improving the patients' Quality of Life by providing the healthier patient counselling and empowering patients with the worthy knowledge regarding their ailments. These kinds of studies should be carried out in the future in all types of morbid conditions so that quality of life of the patients can be improved, better relations will be established between health care professionals including the clinical pharmacist which will be constructive for the upcoming of evolving Clinical Pharmacists.

\section{ACKNOWLEDGEMENT}

Dr. S. Chandra Babu, Associate Professor, RIMS, Kadapa.
M. Venkata Subbaiah, Assistant Professor, P. Rami Reddy Memorial College of Pharmacy, Kadapa.

\section{CONFLICT OF INTEREST}

No conflict of interest are declared.

\section{ABBREVIATION USED}

RIMS: Rajiv Gandhi Institute of Medical Sciences; IEC: Institutional Ethical Committee; HTN: Hypertension; DM: Diabetes Mellitus; COPD: Chronic Obstructive Pulmonary Disease; FVC: Forced expiratory Volume; FEV1: Forced expiratory Volume at one second; TLC: Total Lung Capacity; VC: Vital Capacity; HDL: High Density lipo-protein; LDL: Low Density Lipoprotein; TC: Total Cholesterol; RBS: Random Blood Sugar; FBS: Fasting Blood Sugar; BP: Blood Pressure; IG: Interventional Group; OBG: Observational Group; KAP: Knowledge aptitude and Practice; QOL: Quality of Life; N: No; Y: Yes; M: Month; ANOVA: Analysis of variance. 


\section{REFERENCES}

1. American College of Clinical Pharmacy, The definition of clinical pharmacy, Pharmacotherapy. 2008;28:816-7. http://dx.doi.org/10.1592/phco.28.6.816 ; PMid:18503408.

2. Talasaz AH. The Potential Role of Clinical Pharmacy Services in Patients with Cardiovascular Diseases. Journal of Tehran University Heart Center. 2012;7(2):41-6.

3. Hepler C, Strand L. Opportunities and responsibilities in pharmaceutical care. Am J Hosp Pharm. 1990;47(3):533-43. PMid:2316538.

4. G. Parthasarathi et al. A text book of clinical pharmacy practice; essential concepts and skills, clinical pharmacy in India, 2nd edition, 2012; 1-3.

5. Tipnis HP, Bajaj. a text book of clinical pharmacy, 2nd edition. 2011;4-5.

6. Biradar SS et al. Assessment of pharmacist mediated patient counseling on hypertension incompliance with quality of life in south Indian city. IJRP. 2012;3(1):206-9.

7. Autumn B, et al. The Role of Clinical Pharmacists in Modifying Cardiovascular Disease Risk Factors. INNOVATIONS in Pharmacy. 2013;4(3):129.

8. Mahwi, Obied. Role of the Pharmacetical Care in the Management of Patients with Type 2 Diabetes Mellitus. IJPSR. 2013;4(4):1363-9.

9. Line $\mathrm{A}$ et al. knowledge, attitudes and practices on hypertension in a country in epidemiological transition. Hypertension. 1998;31(5);1136-45. http://dx.doi. org/10.1161/01.HYP.31.5.1136.

10. Das S, Das SK et al. knowledge, attitudes and practices of Stroke in India vs. other developed and developing countries. Ann Indian AcadNeurol. 2013;16(4):488-93.http://dx.doi.org/10.4103/0972-2327.120431

PMid:24339565 PMCid:PMC3841586.

11. Al- Maskar et al. knowledge, attitudes and practices of Diabetic patients in the United Arab Emirates, PLoS one. 2013;8(1):e52857.

12. Rathan SM, et al. Role of clinical pharmacist in impact of patient counseling in asthmatic patients. JGTPS.2013;4(2):1111-7.

13. Gusmao JL, Mion Jr. D, Pierin AMG. Health-related quality of life and blood pressure control in hypertensive patients with and without complications. Clinics. 2009;64(7):619-28. http://dx.doi.org/10.1590/S1807-59322009000700003 ; PMid:19606236 PMCid:PMC2710433.

14. Kehchung $\mathrm{L}$, et al. Assessing the stroke specific $\mathrm{QOL}$ for outcome measurement in stroke rehabilitation: Minimal detectable change and clinically important difference, health and QOL outcomes; 2011;9(1):1.

15. Harvey T. et al. Health related QOL and Type II Diabetes: a study of people living in the bellacoolevally. BCMJ.2006;48(6):272-8.

16. Eanes Delgado Barros Pereiral et al. Asthma control and quality of life in patients with moderate or severe asthma. J Bras Pneumol. 2011;37(6).

PMid:22241026 